\title{
Effect of Pyrisoxazole on Colletotrichum scovillei Infection and Anthracnose on Chili
}

\author{
Y. Y. Gao, X. X. Li, L. F. He, B. X. Li, W. Mu, and F. Liu ${ }^{\dagger}$ \\ Shandong Provincial Key Laboratory for Biology of Vegetable Diseases and Insect Pests, College of Plant Protection, Shandong \\ Agricultural University, Tai'an, Shandong 271018, People's Republic of China
}

\begin{abstract}
Anthracnose caused by Colletotrichum scovillei is one of the most destructive diseases affecting chili production. Disease control mainly relies on conventional fungicides, and repeated exposure to single-site mode-of-action fungicides may pose a risk for the development of resistant isolates within the population. Our previous study suggested that pyrisoxazole has strong inhibitory activity against $C$. scovillei in vitro. However, the effects of pyrisoxazole on the C. scovillei infection process and the performance of pyrisoxazole in the field remain unclear. In this study, pyrisoxazole exhibited strong inhibitory activity against the mycelial growth, appressorium formation, and appressorium diameter of $C$. scovillei, with half maximal effective concentration values of $0.1986,0.0147$, and $0.0269 \mu \mathrm{g} / \mathrm{ml}$, respectively, but had no

preventive and curative activity against anthracnose on chili. Pyrisoxazole decreased the incidence of anthracnose and reduced disease progress. The results of electron microscopy showed that pyrisoxazole can affect the $C$. scovillei infection process by altering mycelial morphology, degrading conidia and germ tubes, suppressing conidial germination and appressorium formation, and enhancing conidiophore production. Pyrisoxazole can be used to effectively control anthracnose under field conditions and increase chili yield; moreover, no phytotoxicity symptoms were observed after treatment. These results provide new insight into the mechanisms by which pyrisoxazole controls disease and suggest that pyrisoxazole is a feasible alternative for the management of anthracnose in chili.
\end{abstract} effect on sporulation, even at the highest concentration of $1.6 \mu \mathrm{g} / \mathrm{ml}$. The baseline sensitivity curves were unimodal with a long right-hand tail. The in vivo data showed that pyrisoxazole provided both
Keywords: Colletotrichum scovillei, infection process, mechanism, pyrisoxazole
Chili (Capsicum spp.) is an important economic crop in tropical, subtropical, and temperate regions (Pickersgill 1997). China is the second largest chili producer and exporter, with a planting area of approximately 1.3 million ha (Li et al. 2009). Anthracnose caused by Colletotrichum scovillei is one of the most destructive diseases in chili production, reducing fruit quality and causing approximately $40 \%$ yield loss (Liao et al. 2012a, b; Lin et al. 2004). C. scovillei can also cause disease in many other economic crops, including apple, citrus, mango, and strawberry (Peres et al. 2005). Given the destructiveness of this pathogen, excellent disease control is required.

Although agricultural practices and biological measures have been implemented for anthracnose control (Kim and Yun 2011; Lamsal et al. 2011; Sang et al. 2013), farmers continue to mainly rely on fungicides. However, the management of chili anthracnose uses a limited number of registered fungicides and is challenging because of the unsatisfactory efficacy of these fungicides (Lewis Ivey et al. 2004; Liu et al. 2013) and resistance (Peres et al. 2002, 2004; Wong and Midland 2007). The selection of relatively new and high-efficacy fungicides is therefore an important decision. Infection by Colletotrichum spp. is initiated upon attachment of spores to the host plant surface, followed by germination and appressorium production and infection of the cuticle. Overall, the spore and appressorium play an important role in this process (Hong et al. 2015), and a fungicide

${ }^{\dagger}$ Corresponding author: F. Liu; fliu@sdau.edu.cn

Funding: This work was supported by grants from the National Key R\&D Program of China (2016YFD0200500) and the Provincial Key Research and Development Program of Shandong (2017CXGC0207).

*The $\boldsymbol{e}$-Xtra logo stands for "electronic extra" and indicates that supplementary materials are published online.

The author(s) declare no conflict of interest.

Accepted for publication 29 August 2019.

(C) 2020 The American Phytopathological Society with high inhibitory activity against spore germination and appressorium formation would have strong potential as an alternative for the control of anthracnose in chili.

Sterol demethylation inhibitor (DMI) fungicides are currently the most important and extensively applied fungicide class in agriculture, with favorable postinfection activity against a broad spectrum of pathogenic fungi (Zhang et al. 2017). DMI fungicides consist of many subclasses, among which imidazoles, triazoles, and pyridines are the most widely used (Chen et al. 2012). Although the triazoles difenoconazole and tebuconazole are currently registered for the control of chili anthracnose, the phytotoxicity of these compounds and associated resistance have limited their use (Wong and Midland 2007). Pyrisoxazole, a pyridine derivative, exhibits strong inhibitory activity against various ascomycetes and basidiomycetes, including Monilinia fructicola, Botrytis cinerea, and Ceratobasidium cerealis (Chen et al. 2012, 2014). In our previous study, pyrisoxazole exhibited superior satisfactory activity against $C$. scoville $i$ than other DMIs in vitro (Gao et al. 2017); however, the effect of pyrisoxazole on the $C$. scoville $i$ infection process and the efficacy of pyrisoxazole in the control of anthracnose under field conditions remain unknown. In addition, pyrisoxazole has not been registered for use against chili anthracnose in China, and information on this compound, including baseline sensitivity and inhibitory activity, will promote fungicide registration.

The objectives of this study were therefore to determine the inhibitory activity of pyrisoxazole against the different developmental stages of $C$. scovillei in vitro, to establish the baseline sensitivity of C. scovillei to this fungicide, to evaluate the effect of pyrisoxazole on the $C$. scovillei infection process on chili fruit, to establish a model to predict the probability of disease severity for different treatments, and to investigate the performance of pyrisoxazole under field conditions.

\section{Materials and Methods}

Fungal isolates and fungicides. During 2015 to 2017, 205 singlespore isolates of $C$. scovillei were collected from different fields located in six major chili production regions in Shandong Province, China. These fields had never been exposed to pyrisoxazole or other 
DMIs. All strains were isolated by the single-spore method and used in the baseline sensitivity assay (Choi et al. 1999). These isolates were identified based on morphology and ITS, GAPDH, ACT, TUB2, CAL, and CHS1 sequences (Diao et al. 2017) and were maintained on potato dextrose agar (PDA; Oxoid, Basingstoke, UK) slants at $4^{\circ} \mathrm{C}$ until use.

For bioactivity and baseline sensitivity analyses, technical-grade pyrisoxazole (93\% active ingredient [a.i.]; Shenyang Research Institute of Chemical Industry) was dissolved in acetone to produce stock solutions and then stored at $4{ }^{\circ} \mathrm{C}$ until use. Formulated pyrisoxazole (25\% effective concentration [EC]; Shenyang Research Institute of Chemical Industry), difenoconazole (10\% WDG; Syngenta Crop Protection Ltd.), myclobutanil (25\% EC; Hebei Zhuocheng Chemical Co. Ltd.), and propiconazole ( $250 \mathrm{~g} /$ liter EC; Shandong Binnong Technology Co. Ltd.) were tested for efficacy against anthracnose in vivo and in field assays.

Inhibitory activity of pyrisoxazole against $\boldsymbol{C}$. scovillei. To evaluate the bioactivity of pyrisoxazole against $C$. scoville $i, 20$ isolates were randomly selected. Six mycelial plugs $(5 \mathrm{~mm}$ in diameter) were cut from the margins of 6-day-old colonies of each isolate and transferred into $250-\mathrm{ml}$ flasks containing $150 \mathrm{ml}$ of potato dextrose broth (PDB; Elite Biotechnology Shanghai Co. Ltd.) with pyrisoxazole at $0,0.01,0.025,0.05,0.1,0.2,0.4,0.8$, or $1.6 \mu \mathrm{g} / \mathrm{ml}$ (Xu et al. 2015). Cultures amended with acetone were used as a control. The flasks were shaken at $150 \mathrm{rpm}$ and $25^{\circ} \mathrm{C}$. After 6 days, the mycelia were collected, washed three times with sterile distilled water, dried at $100^{\circ} \mathrm{C}$ for $12 \mathrm{~h}$, and weighed.

Mycelial plugs ( $5 \mathrm{~mm}$ in diameter) cut from the margins of 6-dayold colonies of each isolate were also transferred upside down onto the center of PDA plates containing $0,0.01,0.025,0.05,0.1,0.2$, $0.4,0.8$, or $1.6 \mu \mathrm{g} / \mathrm{ml}$ pyrisoxazole. After incubation at $25^{\circ} \mathrm{C}$ in the dark for 6 days, the mean colony diameters were measured, the mycelial area was calculated, and spores were scraped from the mycelial surface using $10 \mathrm{ml}$ of sterile distilled water. The spore suspensions were filtered through three layers of cheesecloth, transferred to a 10$\mathrm{ml}$ centrifuge tube, centrifuged at $10,000 \mathrm{rpm}$ for $10 \mathrm{~min}$, and resuspended in $5 \mathrm{ml}$ of sterile distilled water. The spore density per square centimeter of mycelia was determined using a hemocytometer at 100x magnification (Olympus $\mathrm{BX}_{53}$; Beijing Cnrico Technology Co. Ltd.)

Spore suspensions $\left(1 \times 10^{4} / \mathrm{ml}\right)$ were prepared as described above, after which $0.1 \mathrm{ml}$ was spread onto water agar (WA; NanJing SenBeiJia Biotechnology Co. Ltd.) plates amended with pyrisoxazole at concentrations of $0,0.005,0.01,0.02,0.04,0.08,0.16$, or $0.32 \mu \mathrm{g} / \mathrm{ml}$. After incubation for $48 \mathrm{~h}$ at $25^{\circ} \mathrm{C}$ in the dark, appressorium formation was determined at $100 \times$ magnification (Olympus $\left.\mathrm{BX}_{53}\right)$. The appressorium incidence for each treatment was calculated as the number of spores that formed appressoria/the number of germinated spores $\times 100 \%$. In addition, the diameters of 20 appressoria for each replicate were measured under a microscope (Olympus $\mathrm{BX}_{53}$ ) using an image software program (cellSens standard 1.12). Unless otherwise stated, all experiments were repeated three times with four replicates.

Baseline sensitivity to pyrisoxazole. The sensitivity of $C$. scovillei to pyrisoxazole was determined by measuring mycelial growth (205 isolates) and spore germination (100 isolates) (Veloukas and Karaoglanidis 2012; Zhang et al. 2012). In the mycelial growth assay, mycelial plugs ( $5 \mathrm{~mm}$ in diameter) were transferred to PDA plates amended with pyrisoxazole at $0,0.025,0.05,0.1,0.4,0.8$, or $1.6 \mu \mathrm{g} / \mathrm{ml}$. After incubation at $25^{\circ} \mathrm{C}$ in the dark for 6 days, radial growth was measured perpendicularly. In the spore germination test, $0.1 \mathrm{ml}$ of spore suspension was spread onto WA plates containing $0,0.02,0.04,0.06,0.08,0.16$, or $0.32 \mu \mathrm{g}$ of pyrisoxazole $/ \mathrm{ml}$. After incubation for $10 \mathrm{~h}$ at $25^{\circ} \mathrm{C}$ in the dark, 200 to 300 spores were randomly selected from each plate for determination of spore germination (germ tube length over the half-length of spores). In addition, the morphology of the mycelia and spores with different fungicide treatments was observed under a light microscope (Olympus $\mathrm{BX}_{53}$ ) according to previously described methods (Gao et al. 2018).
In vivo test. Immature green chili fruit (Huangxian 7318) with similar size were sprayed with pyrisoxazole at 180,120 , or $90 \mathrm{~g}$ of a.i./ha. Difenoconazole, myclobutanil, and propiconazole as reference fungicides were applied at $180 \mathrm{~g}$ of a.i./ha, and fruit sprayed with sterile distilled water were used as a control. Each treatment was sprayed until runoff using a handheld sprayer (Xinmeir Co. Ltd.). Fungicides were applied $24 \mathrm{~h}$ before fungal inoculation (preventive activity) or after inoculation (curative activity).

For fungal inoculation, a C. scovillei isolate (JY3) with stable pathogenicity was selected, and a spore suspension $\left(1 \times 10^{5} / \mathrm{ml}\right)$ was prepared with PDB as described above. Each fruit was punctured to a depth of $1 \mathrm{~mm}$ with a sterile needle and then inoculated with $15 \mu \mathrm{l}$ of spore suspension (Harp et al. 2014). After inoculation, the tested fruit were incubated in an incubator for 7 days at $25^{\circ} \mathrm{C}$ (12-h photoperiod) with $85 \%$ relative humidity. Disease severity was recorded using the following scale: $0=$ no disease, $1=1$ to $10 \%, 2=11$ to $20 \%, 3=21$ to $30 \%, 4=31$ to $40 \%, 5=41$ to $50 \%, 6=51$ to $60 \%, 7=61$ to $70 \%, 8=71$ to $80 \%$, and $9 \geq 81 \%$, where the percentages represent the diseased area (Mani et al. 2016). Disease severity was calculated as follows:

Disease severity $=[\Sigma($ Number of diseased chili fruit in each scale $\times$ Disease scale $) /($ Total chili fruit $\times 9)] \times 100$

Control efficacy was calculated as follows:

Control efficacy $=($ Disease severity of untreated control group

- Disease severity of fungicide treatment group)/Disease severity of untreated control group $\times 100 \%$

The experiment was repeated four times with three replicates (60 fruit for each replicate).

Field experiments. The chili cultivar Jingxinhong was grown in fields located in Jining, Shandong Province, in 2015, 2016, and 2017. These plants were naturally infected with $C$. scovillei. Chili seedlings were planted and managed according to standard agronomic practices. Twenty-eight plots $(6 \times 5 \mathrm{~m})$ were arranged in a completely randomized block design. The following seven treatments were applied: treatments 1 to 3 , pyrisoxazole at 180,90 , and $45 \mathrm{~g}$ of a.i./ha, respectively; treatments 4 to 6 , difenoconazole, myclobutanil, and propiconazole at $180 \mathrm{~g}$ of a.i./ha, respectively; and treatment 7 , untreated control group. The spray volume was 675 liter/ha; all fungicide solutions were sprayed using a universal MATABI sprayer with a pressure of $0.3 \mathrm{MPa}$. The fungicides were applied in mid-July three times at 10-day intervals.

Disease development was investigated before the first fungicide application and 10 days after each fungicide application. The disease severity and control efficacy were calculated as described above 10 days after the last treatment. To determine the yield of each treatment, in September 2015, 2016, and 2017, ripe and marketable chili fruit (red color with no diseased spots) were harvested from 30 plants in each plot and dried in the sun until a constant weight was obtained (with weight variations $<0.1 \%$ ). The yield of each treatment was transformed into grams per plant (Amador-Ramírez et al. 2007).

To evaluate the phytotoxicity of pyrisoxazole, difenoconazole, myclobutanil, and propiconazole, the fruit setting rate and fruit size were assessed. The chili cultivar Jingxinhong was planted and managed according to standard agronomic practices in a greenhouse, and the spray dates and fungicide dosages were similar to those described above. Thirty plants were randomly selected from each plot, and the indexes were evaluated 10 days after the last treatment.

Effect of pyrisoxazole on the $\boldsymbol{C}$. scovillei infection process on chili fruit. Immature green chili fruit were transferred to plastic boxes lined with saturated gauze. The middle of each fruit was inoculated with $15 \mu \mathrm{l}$ of $C$. scovillei spore suspension $\left(1 \times 10^{5} / \mathrm{ml}\right)$. These fruit were sprayed with pyrisoxazole ( $180 \mathrm{~g}$ of a.i./ha) using a handheld sprayer before and after fungal inoculation. Control fruit were sprayed with sterile distilled water. Samples were collected for scanning electron microscopy (SEM) analysis after 24, 48, 72, 96, and 
$120 \mathrm{~h}$. Before observation, the samples were treated by following previously reported methods (Wang et al. 2011).

Data analysis. All data were processed using SAS software (version 9.2; SAS Institute, Cary, NC). Results were assessed using Shapiro-Wilk and Levene variance equality tests to ensure the normal distribution and homoscedasticity of variances. Half maximal effective concentration $\left(\mathrm{EC}_{50}\right)$ values (in vitro tests and baseline sensitivity assays) were estimated by a linear regression analysis between the percentage of relative growth and the $\log _{10}$ fungicide concentration. Analysis of variance was used to analyze the data of disease severity and control efficacy in the in vivo trials and field experiments. The Tukey honestly significant difference test $(P=0.05)$ was employed to determine significant differences between treatments.

To predict the probability for disease rating of each treatment, the in vivo rating data were analyzed using a multinomial generalized linear model and a generalized linear mixed model (Supplementary File S1). Compared with the logit and probit models, the multinomial model could be used for analysis of three or more response categories. The model was regarded as a predictor that can be used to predict the performance of fungicides in the field and was established by SAS (version 9.2; SAS Institute) using the GLIMMIX procedure. The $\eta$ is a link function that was directly affected by treatment effects and determined the probability of disease rating. In this study, the disease severity has 10 categories: $\mathrm{Y}_{0 \mathrm{i}}$ (number of fruit rated 0 from the ith treatment), $Y_{1 i}, Y_{2 i}, Y_{3 i}, Y_{4 i}, Y_{5 i}, Y_{6 i}, Y_{7 i}, Y_{8 i}$, and $Y_{9 i}$ (number of fruit rated 9 from the ith treatment). The probability for each rating is represented by $\pi_{0 \mathrm{i}}, \pi_{1 \mathrm{i}}, \pi_{2 \mathrm{i}}, \pi_{3 \mathrm{i}}, \pi_{4 \mathrm{i}}, \pi_{5 \mathrm{i}}, \pi_{6 \mathrm{i}}, \pi_{7 \mathrm{i}}, \pi_{8 \mathrm{i}}$, and $\pi_{9 \mathrm{i}}$. In the prediction model, $\mathrm{Y}_{1 \mathrm{i}}, \mathrm{Y}_{2 \mathrm{i}}, \mathrm{Y}_{3 \mathrm{i}}, \mathrm{Y}_{4 \mathrm{i}}, \mathrm{Y}_{5 \mathrm{i}}, \mathrm{Y}_{6 \mathrm{i}}, \mathrm{Y}_{7 \mathrm{i}}, \mathrm{Y}_{8 \mathrm{i}}$, and $\mathrm{Y}_{9 \mathrm{i}}$ had a multinomial distribution for $\mathrm{i}$ and the linear predictor was shown as follows:

$$
\begin{gathered}
\eta_{0 \mathrm{i}}=\log \left[\frac{\pi_{0 \mathrm{i}}}{1-\pi_{0 \mathrm{i}}}\right]=\beta_{00}+\operatorname{Tr}_{0 \mathrm{i}} \\
\eta_{1 \mathrm{i}}=\log \left[\frac{\pi_{0 \mathrm{i}}+\pi_{1 \mathrm{i}}}{1-\left(\pi_{0 \mathrm{i}}+\pi_{1 \mathrm{i}}\right)}\right]=\beta_{01}+\operatorname{Tr}_{1 \mathrm{i}} \\
\eta_{2 \mathrm{i}}=\log \left[\frac{\pi_{0 \mathrm{i}}+\pi_{1 \mathrm{i}}+\pi_{2 \mathrm{i}}}{1-\left(\pi_{0 \mathrm{i}}+\pi_{1 \mathrm{i}}+\pi_{2 \mathrm{i}}\right)}\right]=\beta_{02}+\operatorname{Tr}_{2 \mathrm{i}} \ldots . . \\
\eta_{9 \mathrm{i}}=\log \left[\frac{\pi_{0 \mathrm{i}}+\pi_{1 \mathrm{i}}+\pi_{2 \mathrm{i}}+\pi_{3 \mathrm{i}}+\pi_{4 \mathrm{i}}+\pi_{5 \mathrm{i}}+\pi_{6 \mathrm{i}}+\pi_{7 \mathrm{i}}+\pi_{8 \mathrm{i}}+\pi_{9 \mathrm{i}}}{1-\left(\pi_{0 \mathrm{i}}+\pi_{1 \mathrm{i}}+\pi_{2 \mathrm{i}}+\pi_{3 \mathrm{i}}+\pi_{4 \mathrm{i}}+\pi_{5 \mathrm{i}}+\pi_{6 \mathrm{i}}+\pi_{7 \mathrm{i}}+\pi_{8 \mathrm{i}}+\pi_{9 \mathrm{i}}\right)}\right] \\
=\beta_{09}+\operatorname{Tr}_{9 \mathrm{i}}
\end{gathered}
$$

where $\beta_{0 c}$ is the interceptor and $\operatorname{Trt}_{i}$ is the treatment effect.
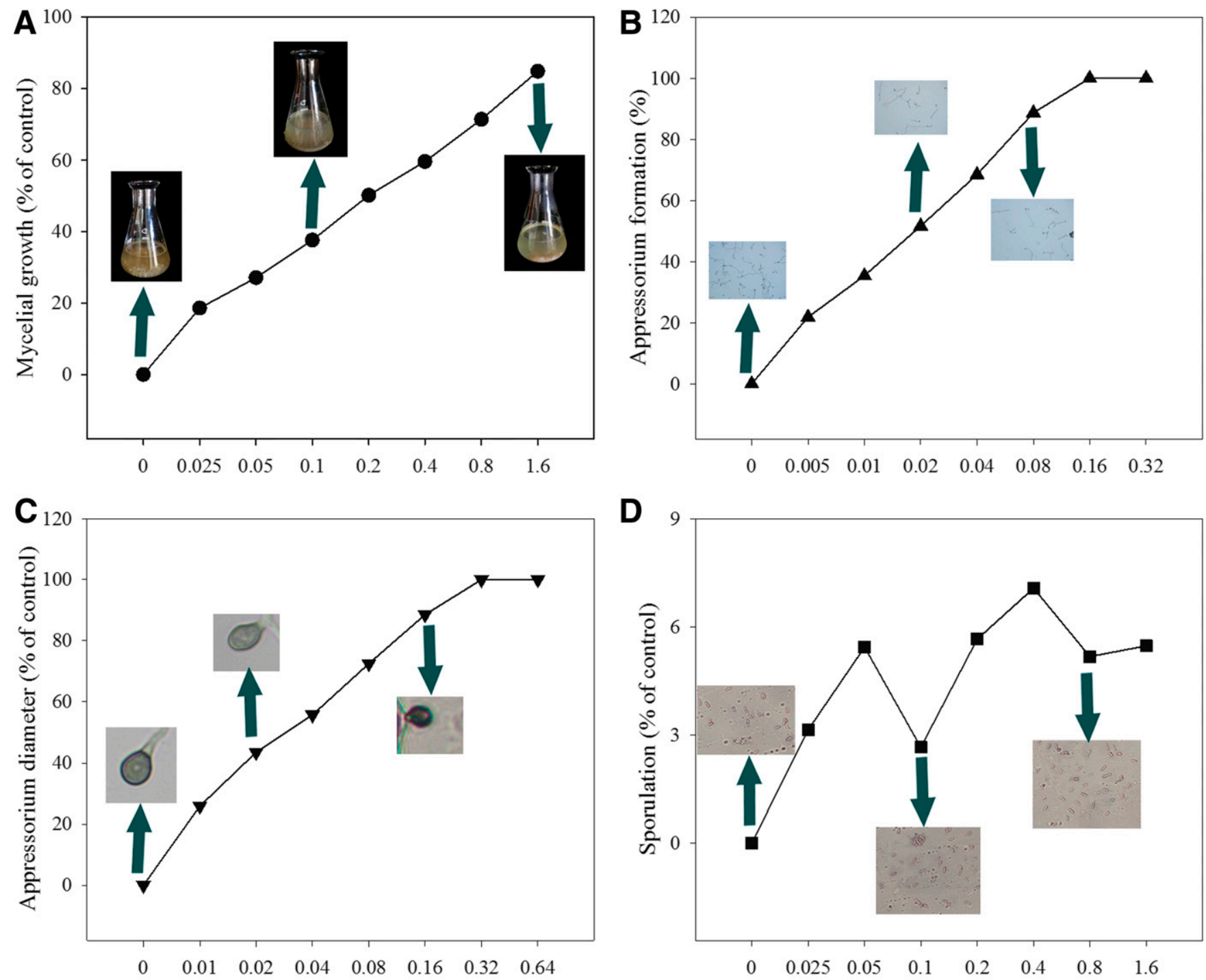

Fungicide concentrations $(\mathrm{mg} / \mathrm{L})$

Fig. 1. Inhibitory activity of pyrisoxazole in terms of A, mycelial yield, B, appressorium formation, C, appressorium diameter, and D, sporulation of Colletotrichum scovillei. 


\section{Results}

Inhibitory activity of pyrisoxazole against $C$. scovillei in vitro. The 20 isolates evaluated showed similar biological responses to all of the tested concentrations of pyrisoxazole. Therefore, for each tested concentration, the mean values for inhibition of mycelial growth, sporulation, appressorium formation, and appressorium growth were calculated and analyzed. The inhibition rates for appressorium formation and appressorium diameter were $>90 \%$ at a concentration of $0.16 \mu \mathrm{g} / \mathrm{ml}$, whereas that of mycelial growth reached $84.85 \%$ at $1.6 \mu \mathrm{g} / \mathrm{ml}$. Moreover, pyrisoxazole had no effect on $C$. scovillei sporulation, even at the highest concentration (Fig. 1). The $\mathrm{EC}_{50}$ values for inhibition of mycelial growth, appressorium formation, and appressorium diameter were 0.1986, 0.0147, and $0.0269 \mu \mathrm{g} / \mathrm{ml}$, respectively.

Baseline sensitivity to pyrisoxazole. The sensitivity of the 205 C. scovillei isolates to pyrisoxazole was assessed based on mycelial growth. The baseline sensitivity curve was unimodal with a long right-hand tail (Fig. 2A). The $\mathrm{EC}_{50}$ values ranged from 0.0444 to $0.2480 \mu \mathrm{g} / \mathrm{ml}$, with a mean of $0.1207 \mu \mathrm{g} / \mathrm{ml}$. The difference between the highest and lowest $\mathrm{EC}_{50}$ values was 5.59-fold.

In the spore germination assay, the frequency distribution of $\mathrm{EC}_{50}$ values fit a unimodal curve; the values ranged from 0.0901 to $1.3226 \mu \mathrm{g} / \mathrm{ml}$, with a mean value of $0.4104 \mu \mathrm{g} / \mathrm{ml}$. A relatively high variation factor of 14.68 was observed (Fig. 2B). Overall, there was no significant difference in fungicide sensitivity for isolates collected in 2015, 2016, and 2017 (Fig. 3). The mean $\mathrm{EC}_{50}$ values for mycelial growth inhibition were $0.1358,0.1235$, and $0.1103 \mu \mathrm{g} / \mathrm{ml}$, and those for spore germination inhibition were $0.4703,0.4253$, and $0.3337 \mu \mathrm{g} / \mathrm{ml}$ for 2015,2016 , and 2017, respectively (Fig. 3).

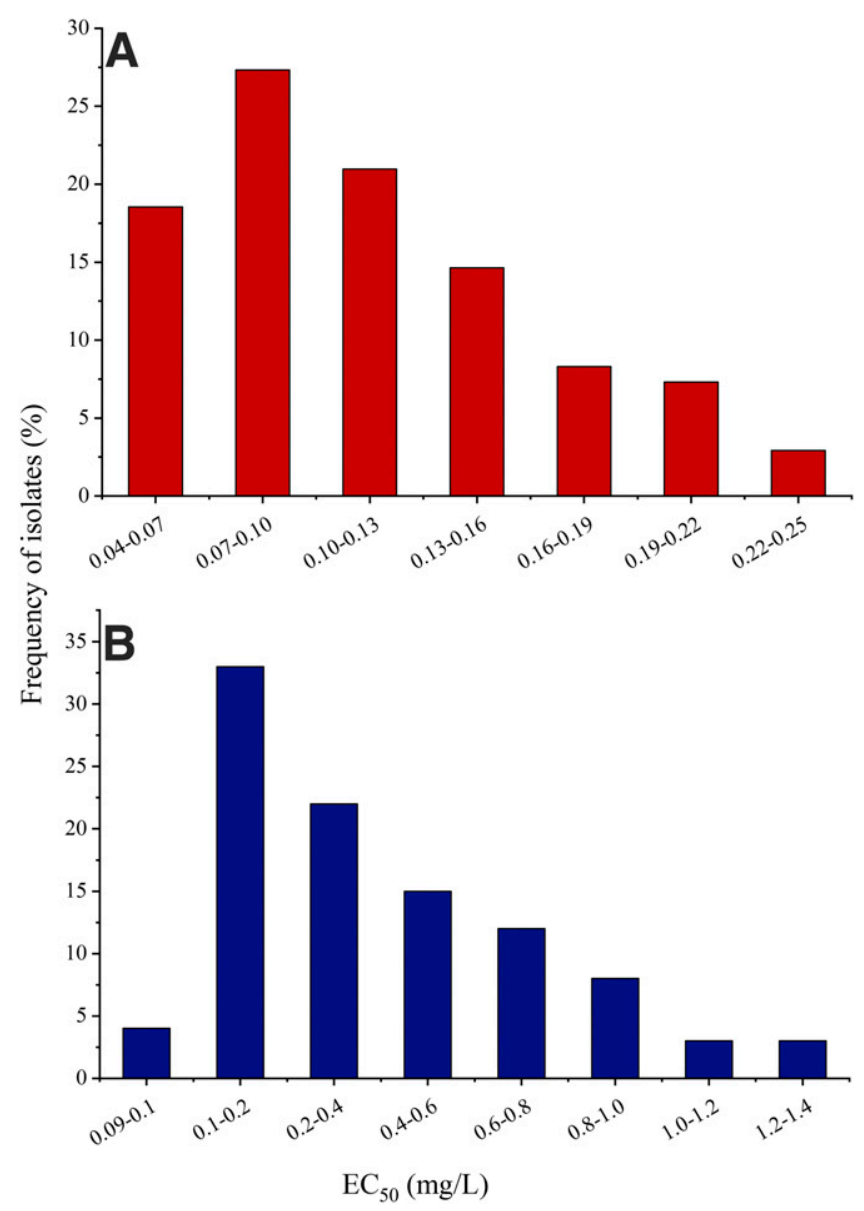

Fig. 2. Frequency distribution of the half maximal effective concentration $\left(E_{50}\right)$ values of pyrisoxazole for Colletotrichum scovillei isolates in terms of $\mathbf{A}$, mycelial growth and B, spore germination.
Effect of pyrisoxazole on the mycelial and conidial morphology of $C$. scovillei. Compared with the untreated control group, mycelium development and spore germination of $C$. scovillei were severely affected by pyrisoxazole. After fungicide treatments, the offshoot of the top of the mycelium was short and decreased in number (Fig. 4E); the mycelia were contorted, and protuberances appeared from the diaphragm (Fig. 4D). The branches of treated germ tubes were decreased in number and swollen (Fig. 4F).

In vivo trials. Pyrisoxazole exhibited both preventive and curative activity against anthracnose on chili fruit. In preventive tests, pyrisoxazole at $180 \mathrm{~g}$ of a.i./ha showed much better preventive control of $C$. scovillei than the difenoconazole, myclobutanil, and propiconazole treatments at $180 \mathrm{~g}$ of a.i./ha, with efficacies of 75.6, $62.4,70.0$, and $67.4 \%$, respectively (Table 1). For the curative assays, applications of pyrisoxazole at 180 and $120 \mathrm{~g}$ of a.i./ha also provided high control efficacy, with values of 71.3 and $67.8 \%$, respectively. The efficacies of myclobutanil and propiconazole showed no significant difference with pyrisoxazole at $180 \mathrm{~g}$ of a.i./ha (Table 1). Furthermore, it was shown that the preventive activity was stronger than the curative activity. In addition, pyrisoxazole significantly decreased the expansion and incidence of anthracnose compared with the control group. The probability of a rating of 9 for pyrisoxazole ranged from 0 to 0.0482 , which was lower than that for the control group (0.1450 to 0.1734) (Supplementary Tables S1 and S2). Sporulation on the fruit after fungicide treatment showed no significant difference from that on the untreated control fruit.

Field experiments. In field trials, pyrisoxazole applied at $180 \mathrm{~g}$ of a.i./ha exhibited favorable efficacy, with control efficiencies of 64.6, 70.7, and 66.9\% in 2015, 2016, and 2017, respectively. Furthermore, low efficacy from 39.2 to $59.1 \%$ for the control of chili anthracnose was observed upon decreasing the application dosage of pyrisoxazole (Fig. 5). The efficacies of the reference fungicides difenoconazole, myclobutanil, and propiconazole ranged from 50.5 to 52.7 , 53.4 to 66.0 , and 49.0 to $58.1 \%$, respectively, which were lower than that of pyrisoxazole at the highest dosage. More importantly, the disease severity in 2015 before fungicide application was greater than that in 2016 and 2017, leading to the lowest efficacy being observed in 2015. These results indicate that determination of the optimal application times for control of chili anthracnose is necessary. The highest yields per plant were observed in plots treated with pyrisoxazole at $180 \mathrm{~g}$ of a.i./ha, and these yields were significantly higher (23.6 to $27.3 \% ; P \leq 0.0397$ ) than those in the control group. However, there were no significant differences $(P \geq 0.9711)$ between the other fungicide treatments and the control group in terms of chili yield (Fig. 5).

No detrimental effects on chili were observed for pyrisoxazole, difenoconazole, myclobutanil, and propiconazole, with no significant difference in fruit number, fruit length, and fruit width between the fungicide treatments and the control group (Fig. 6). These results suggest that pyrisoxazole may be a safe and highly effective alternative for anthracnose management.

Effect of pyrisoxazole on the $C$. scovillei infection process on chili fruit. Pyrisoxazole exhibited high efficacy in the management of chili anthracnose, and differences in the mechanisms by which pyrisoxazole controls disease between the preventive and curative tests were observed. In the preventive assay, spore germination, germ tube length, and appressorium formation were significantly decreased (Fig. 7A). The spores were shriveled and lost infection ability, although the morphology of the germ tubes was not obviously changed. In the curative test, in addition to reduced spore germination and germ tube length, the spores and germ tubes were shriveled and degraded (Fig. 7B). Appressorium formation, cuticle penetration, mycelial differentiation, and spore binding to target organisms were inhibited by pyrisoxazole, which limited mycelial colonization and expansion. The sporulation process was also observed by SEM. After pyrisoxazole treatment, the branches of the conidiophores increased in number. In addition, the observed abnormal development of mycelia at $120 \mathrm{~h}$ after fungicide treatment suggested that pyrisoxazole had long-term residual activity. 


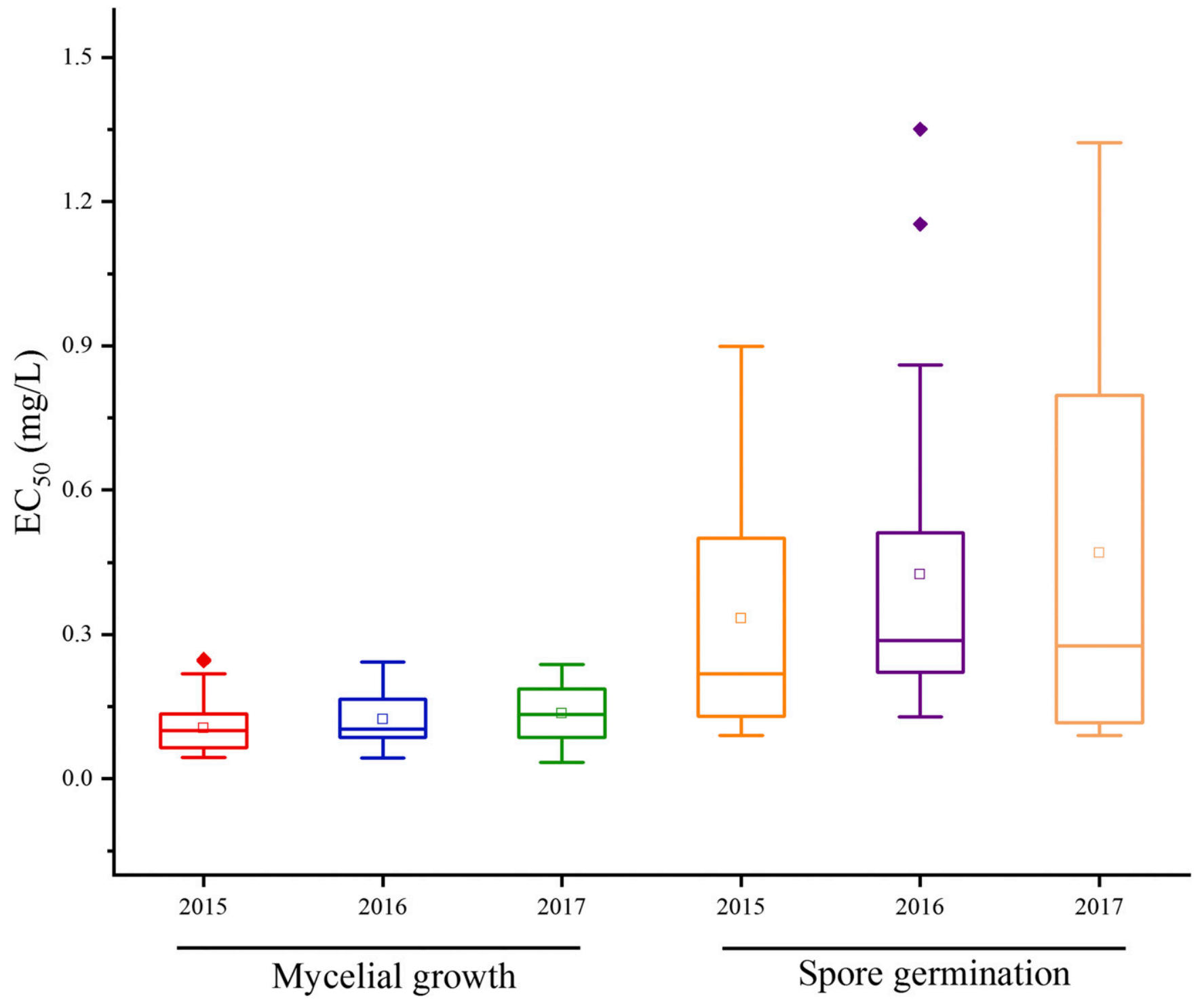

Fig. 3. Variation in half maximal effective concentration $\left(\mathrm{EC}_{50}\right)$ values for isolates collected in 2015, 2016, and 2017.
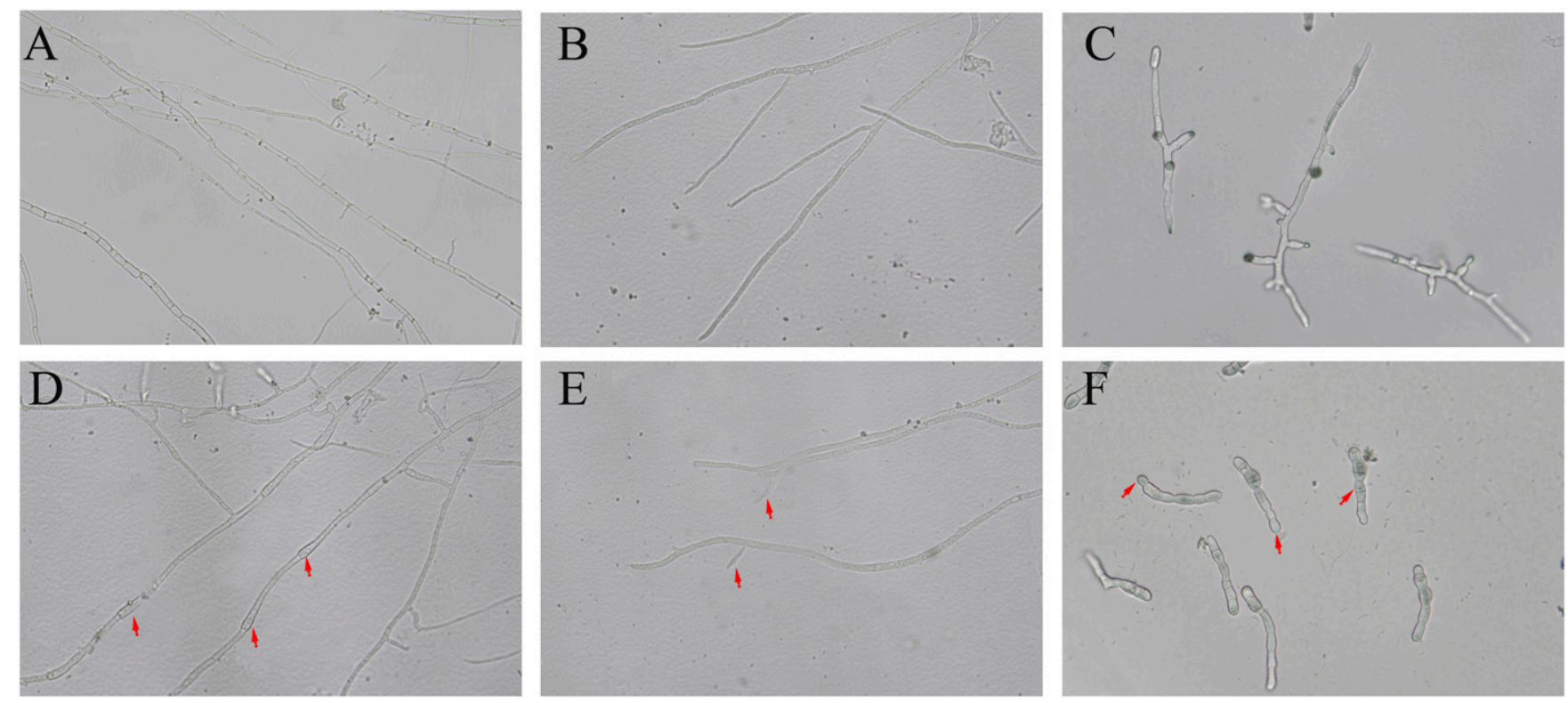

Fig. 4. Effect of pyrisoxazole on mycelial and conidial morphology of Colletotrichum scovillei. A, B, and C, Not treated with pyrisoxazole. D, Diaphragm presenting protuberances. E, Short and increasing tip branches. F, Distorted germ tube. 


\section{Discussion}

Pyrisoxazole is a typical $14-\alpha$ demethylase inhibitor that inhibits the synthesis of sterols (Chen et al. 2014). In general, demethylase inhibitors are known to inhibit mycelial growth more strongly than they inhibit spore germination (Sisler and Ragsdale 1984), because spores can reserve enough sterols to complete germination (Pontzen and Scheinpflug 1989). For example, pyrisoxazole had no effect on the spore germination of $M$. fructicola (Chen et al. 2014) or B. cinerea (Zhu et al. 2016). However, the results of our study showed that pyrisoxazole was effective at inhibiting spore germination in $\mathrm{C}$. $\mathrm{sco}$ villei. This interesting result may be attributed to the stage at which pathogens begin sterol synthesis. The spores of some pathogenic fungi can synthesize sterols in the early stage of spore germination, whereas sterol synthesis in other pathogens is initiated at the end

Table 1. Preventive and curative effects of pyrisoxazole on chili anthracnose in vivo ${ }^{\mathrm{x}}$

\begin{tabular}{|c|c|c|c|c|c|}
\hline \multirow[b]{2}{*}{ Treatment } & \multirow[b]{2}{*}{ Dose (g of a.i./ha) $)^{y}$} & \multicolumn{2}{|c|}{ Preventive efficacy $(\%)$} & \multicolumn{2}{|c|}{ Curative efficacy (\%) } \\
\hline & & Disease severity & Control efficacy & Disease severity & Control efficacy \\
\hline Pyrisoxazole & 180 & $4.2 \mathrm{e}$ & $75.6 \mathrm{a}$ & $5.9 \mathrm{c}$ & $71.3 \mathrm{a}$ \\
\hline Pyrisoxazole & 120 & $5.3 \mathrm{~d}$ & $69.1 \mathrm{~b}$ & $6.7 \mathrm{bc}$ & $67.8 \mathrm{ab}$ \\
\hline Pyrisoxazole & 90 & $6.7 \mathrm{~b}$ & $61.4 \mathrm{~d}$ & $7.8 \mathrm{~b}$ & $62.1 \mathrm{~b}$ \\
\hline Difenoconazole & 180 & $6.5 \mathrm{bc}$ & $62.4 \mathrm{~cd}$ & $7.7 \mathrm{~b}$ & $62.3 \mathrm{~b}$ \\
\hline Myclobutanil & 180 & $5.2 \mathrm{de}$ & $70.0 \mathrm{~b}$ & $6.5 \mathrm{bc}$ & $68.2 \mathrm{a}$ \\
\hline Propiconazole & 180 & $5.6 \mathrm{~cd}$ & $67.4 \mathrm{bc}$ & $7.0 \mathrm{bc}$ & $65.9 \mathrm{ab}$ \\
\hline Water control & - & $17.3 \mathrm{a}$ & - & $20.5 \mathrm{a}$ & - \\
\hline$P$ value & - & 0.0001 & 0.0001 & 0.0001 & 0.0004 \\
\hline $\operatorname{HSD}(P=0.05)^{\mathrm{z}}$ & - & 0.99 & 5.6 & 1.4 & 5.8 \\
\hline
\end{tabular}

${ }^{x}$ Mean values followed by the same letter are not significantly different according to the Tukey test at $P=0.05$.

$\mathrm{y}$ a.i. $=$ active ingredient.

${ }^{\mathrm{z}} \mathrm{HSD}=$ honestly significant difference.
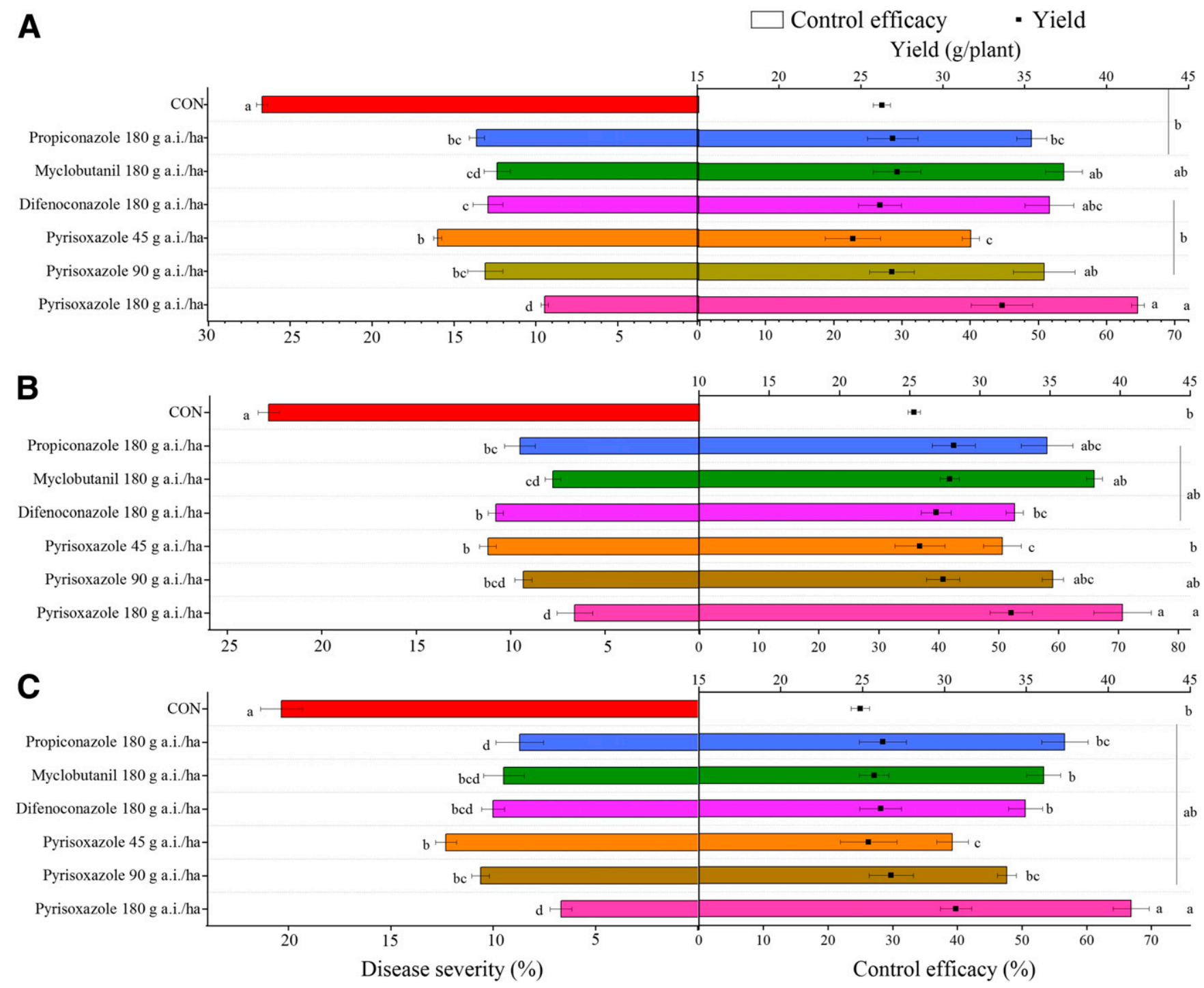

Fig. 5. Efficacy of pyrisoxazole, difenoconazole, myclobutanil, and propiconazole against chili anthracnose under field conditions in A, 2015, B, 2016, and C, 2017. CON = control and a.i. $=$ active ingredient. 
of germ tube elongation (Pontzen and Scheinpflug 1989). We speculate that sterol biosynthesis in $C$. scovillei starts during the early stage of spore germination, which suggests that pyrisoxazole can provide both preventive and curative activities against chili anthracnose. The different responses of $C$. scoville $i$ to pyrisoxazole provide new evidence to explain why this pathogen is regarded as having a low risk for development of resistance to fungicides.

Establishing baseline sensitivity is vitally important for monitoring changes in fungicide sensitivity and for resistance management (Russel 2004). In the present study, the baseline sensitivity of $C$. scovillei to pyrisoxazole was established. Because the tested fungal populations had never been exposed to any DMIs, the sensitivity data can be used as a baseline for monitoring changes in the sensitivity of C. scovillei to pyrisoxazole. The low mean $\mathrm{EC}_{50}$ values for pyrisoxazole in the inhibition of mycelial growth and spore germination of C. scovillei demonstrated that pyrisoxazole may have satisfactory preventive and curative activity against chili anthracnose. Furthermore, the sensitivity distributions for pyrisoxazole were unimodal with long right-hand tails, indicating that $C$. scoville $i$ has the potential for developing resistance to pyrisoxazole (Brent and Hollomon

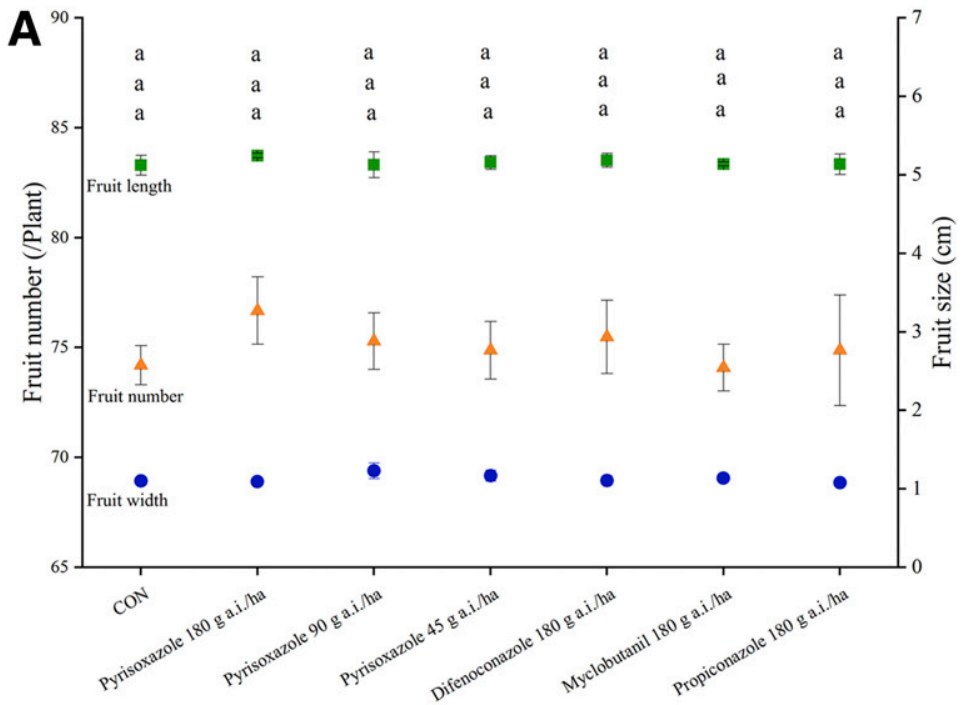

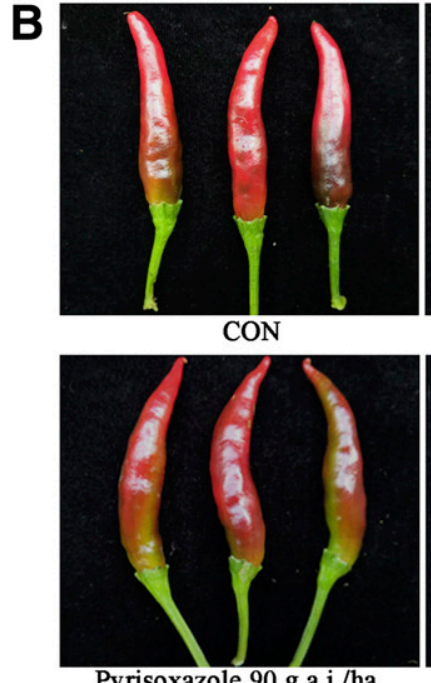

Pyrisoxazole $90 \mathrm{~g}$ a.i./ha

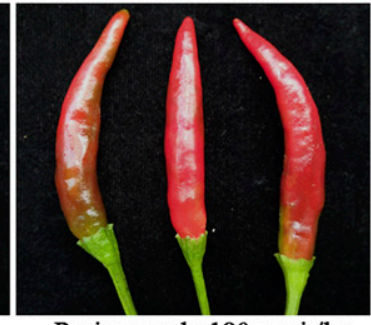

Pyrisoxazole $180 \mathrm{~g}$ a.i./ha

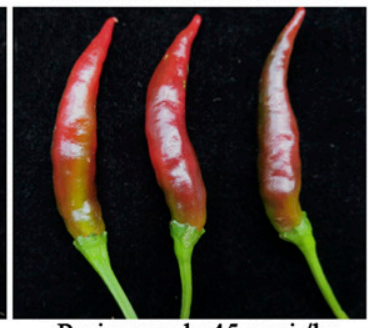

Pyrisoxazole $45 \mathrm{~g}$ a.i./ha

Fig. 6. Effects of all fungicide treatments on the number, length, and width of chili fruit. A, Detail data from phytotoxicity trials. B, Growth characteristics of chili fruit after treatment with pyrisoxazole. $\mathrm{CON}=$ control and a.i. = active ingredient.

A $24 \mathrm{~h}$

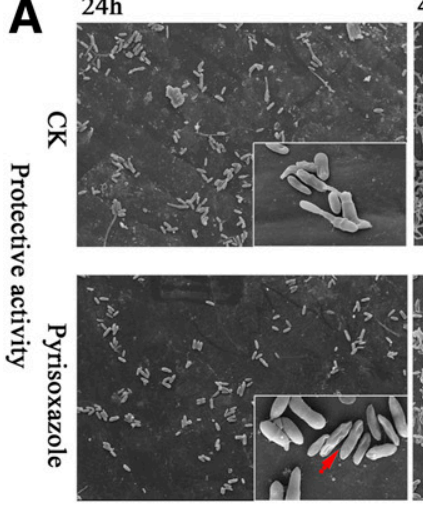

$48 \mathrm{~h}$
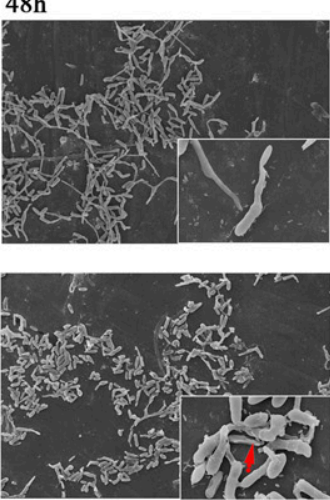

$72 \mathrm{~h}$
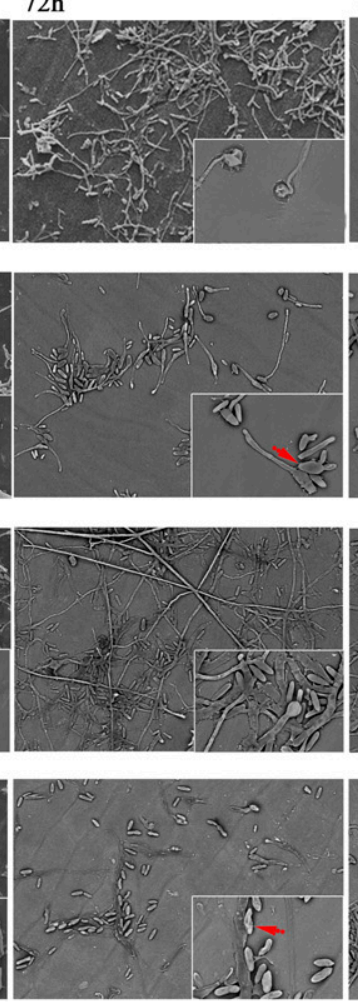

$96 \mathrm{~h}$
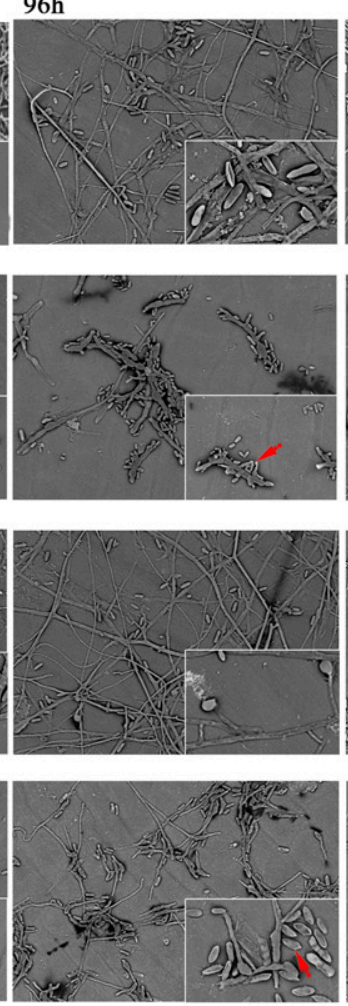

$120 \mathrm{~h}$
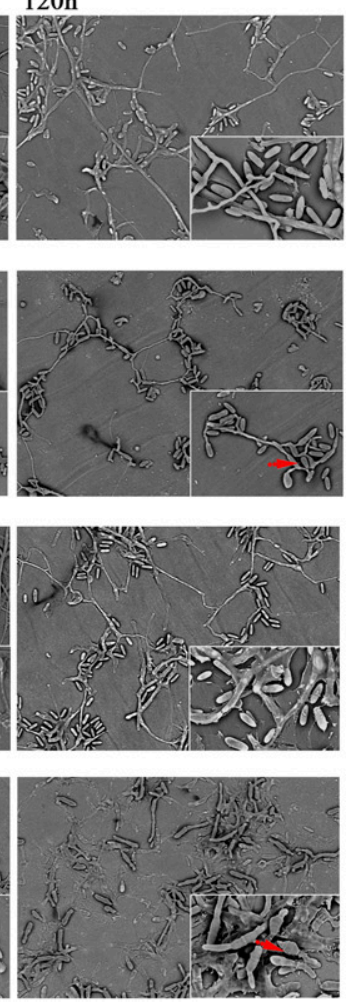

Fig. 7. Effect of pyrisoxazole on the Colletotrichum scovillei infection process on chili fruit. A, The preventive activity of pyrisoxazole against Colletotrichum scovillei, including decreased spore germination, germ tube length, appressorium formation and spore binding to the target organism, and increased branch number of conidial peduncles and wrinkled spores. B, Curative activity of pyrisoxazole for the management of Colletotrichum scovillei, consisting of reduced spore germination, germ tube length, appressorium formation, cuticle penetration, and mycelial differentiation as well as shriveled and degraded spores and germ tubes. CK = control group. 
2015). Hence, it will be crucial to monitor the sensitivity of $C$. scoville $i$ to pyrisoxazole in the future.

Whether a fungicide has the potential to be a favorable tool for disease management depends on the inhibitory activity of the fungicide against the developmental stages of the pathogen. Spores and appressoria play a key role in the infection process of the pathogen, and the substantial inhibitory activity of pyrisoxazole against $C$. scovillei appressorium formation and spore germination suggest that this compound may be a potent alternative for the control of anthracnose. The effect of pyrisoxazole on the $C$. scovillei infection process on chili fruit was observed by SEM. The results indicated that pyrisoxazole can reduce spore germination and germ tube length, and the spores and germ tubes were shriveled and degraded after fungicide treatments. Appressorium formation, mycelial differentiation, and penetration were inhibited by pyrisoxazole, impairing the expansion of disease lesions. These findings provide new insight into the effect of pyrisoxazole on the infection mechanism of $C$. scovillei on chili. In addition, pyrisoxazole promoted the production of conidiophores, which may explain the lack of difference in sporulation among all of the treatments.

The in vivo tests showed that pyrisoxazole possesses both preventive and curative activity against chili anthracnose, which indicated that pyrisoxazole may be popular in modern agriculture because it can prevent the occurrence of disease. Moreover, the probability of a rating from 6 to 9 was seldom observed after fungicide treatment, which showed that pyrisoxazole can inhibit the expansion of disease lesions. In addition, pyrisoxazole also significantly decreased the severity and occurrence of anthracnose compared with the other tested fungicides, mainly owing to the penetration and mobility of pyrisoxazole in target organisms (Chen et al. 2014). Field experiments also showed that pyrisoxazole provided more satisfactory efficacy than the reference fungicides. This finding was consistent with previous studies in which pyrisoxazole exhibited excellent efficacy against tomato gray mold and tomato leaf mold in the field (Liu et al. 2004; Si et al. $2004 \mathrm{a}, \mathrm{b}$ ). In addition, there was a positive relationship between disease control efficacy and chili yield, which demonstrated that anthracnose is a major threat to chili yield. The benzimidazole fungicide carbendazim is the most widely used fungicide for the control of chili anthracnose in the field, and a previous study showed that pyrisoxazole had no cross-resistance with carbendazim in $B$. cinerea (Zhu et al. 2016). Based on baseline sensitivity data, to avoid the occurrence of fungicide resistance, pyrisoxazole should be used as a preventive fungicide or in tank mixtures with other effective pesticides with different modes of action. These results provide sufficient evidence to support the use of pyrisoxazole as a satisfactory alternative for protecting chili from $C$. scovillei.

In summary, pyrisoxazole exhibited high inhibitory activity against the different developmental stages of $C$. scovillei in vitro, with excellent efficacy against anthracnose under control conditions and in the field. The mechanisms by which pyrisoxazole prevents $C$. scovillei infection mainly include decreased spore germination and germ tube length, shriveled and degraded spores and germ tubes, reduction in appressorium formation, and prevention of mycelial differentiation and penetration. These results suggest that pyrisoxazole might be an excellent alternative for protecting chili from anthracnose, and the findings provide new insight into the mechanism of action of pyrisoxazole for disease management.

\section{Literature Cited}

Amador-Ramírez, M. D., Mojarro-Dávila, F., and Velásquez-Valle, R. 2007. Efficacy and economics of weed control for dry chill pepper. Crop Prot. 26: 677-682.

Brent, K. J., and Hollomon, D. W. 2015. Fungicide Resistance: The Assessment of Risk. FRAC Monograph No. 2, 2nd (rev) ed. Fungicide Resistance Action Committee, Brussels, Belgium. https://www.frac.info/docs/default-source/publications/ monographs/monograph-2.\%20pdf?sfvrsn $=8 \&$ sfvrsn $=8$

Chen, F., Han, P., Liu, P., Si, N., Liu, J., and Liu, X. 2014. Activity of the novel fungicide SYP-Z048 against plant pathogens. Sci. Rep. 4:6473.

Chen, F. P., Fan, J. R., Zhou, T., Liu, X. L., Liu, J. L., and Schnabel, G. 2012. Baseline sensitivity of Monilinia fructicola from China to the DMI fungicide SYP-Z048 and analysis of DMI-resistant mutants. Plant Dis. 96: 416-422.
Choi, Y. W., Hyde, K. D., and Ho, W. 1999. Single spore isolation of fungi. Fungal Divers. 3:29-38.

Diao, Y. C., Zhang, C., and Liu, F. 2017. Colletotrichum species causing anthracnose disease of chili in China. Persoonia 38:20-37.

Gao, Y., He, L., Li, X., Lin, J., Mu, W., and Liu, F. 2018. Toxicity and biochemical action of the antibiotic fungicide tetramycin on Colletotrichum scovillei. Pestic. Biochem. Physiol. 147:51-58.

Gao, Y. Y., He, L. F., Li, B. X., Lin, J., Mu, W., and Liu, F. 2017. Identification of the pathogen causing pepper anthracnose in Shandong province and screening of highly effective fungicides. Sci. Agr. Sin. 8:1452-1464.

Harp, T., Kuhn, P., Roberts, P. D., and Pernezny, K. L. 2014. Management and cross-infectivity potential of Colletotrichum acutatum, causing anthracnose on bell pepper in Florida. Phytoparasitica 42:31-39.

Hong, J. K., Yang, H. J., Jung, H., Dong, J. Y., Sang, M. K., and Jeun, Y. C. 2015. Application of volatile antifungal plant essential oils for controlling pepper fruit anthracnose by Colletotrichum gloeosporioides. Plant Pathol. J. 31:269-277.

Kim, S. T., and Yun, S. C. 2011. Biocontrol with Myxococcus sp. KYC 1126 against anthracnose in hot pepper. Plant Pathol. J. 27:156-163.

Lamsal, K., Kim, S. W., Jung, J. H., Kim, Y. S., Kim, K. S., and Lee, Y. S. 2011. Application of silver nanoparticles for the control of Colletotrichum species in vitro and pepper anthracnose disease in field. Mycobiology 39:194-199.

Lewis Ivey, M. L., Navadiaz, C., and Miller, S. A. 2004. Identification and management of Colletotrichum acutatum on immature bell peppers. Plant Dis. 88:1198-1204.

Li, Q., Han, Z., and Zhang, C. 2009. Status and development trends of hot pepper industry home and abroad. Hubei Agr. Sci. 9:2278-2281.

Liao, Y., Chen, Y., Chen, K., Kuo, C., Chung, R., and Lee, M. H. 2012a. Formation of highly branched hyphae by Colletotrichum acutatum, within the fruit cuticles of Capsicum spp. Plant Pathol. 61:262-270.

Liao, Y., Chen, Y., Chen, K., Wang, C., Sheu, M., and Kuo, K. C. 2012b. Characterization of three Colletotrichum acutatum, isolates from Capsicum spp. Eur. J. Plant Pathol. 133:599-608.

Lin, Q., Lv, Z., and Huang, R. 2004. Screening of pepper germplasm for resistance to TMV, CMV, Phytophthora blight and anthracnose. Southwest China J. Agro. Sci. 18:108-110.

Liu, B., Wang, L. Y., Huang, X. G., Cui, R. Q., Song, S. L., and University, J. A. 2013. Identification of a new anthracnose of peppers and screening of fungicides. Biol. Disast. Sci. 36:262-264.

Liu, L., Si, G., Chen, L., Zhang, M., and Zhang, J. 2004. Biological activity against tomato leaf mold and application of a novel fungicide, SYP-Z048 (III). China J. Pesticides 43:103-105.

Mani, K. K., Hollier, C. A., and Groth, D. E. 2016. Effect of planting date, fungicide timing and cultivar susceptibility on severity of narrow brown leaf spot and yield of rice. Crop Prot. 90:186-190.

Peres, N. A., Timmer, L. W., Adaskaveg, J. E., and Correll, J. C. 2005. Lifestyles of Colletotrichum acutatum. Plant Dis. 89:784-796.

Peres, N. A. R., Souza, N. L., Peever, T. L., and Timmer, L. W. 2004. Benomyl sensitivity of isolates of Colletotrichum acutatum and C. gloeosporioides from citrus. Plant Dis. 88:125-130.

Peres, N. A. R., Souza, N. L., Zitko, S. E., and Timmer, L. W. 2002. Activity of benomyl for control of post bloom fruit drop of citrus caused by Colletotrichum acutatum. Plant Dis. 86:620-624.

Pickersgill, B. 1997. Genetic resources and breeding of Capsicum spp. Euphytica 96:129-133.

Pontzen, R., and Scheinpflug, H. 1989. Effects of triazole fungicides on sterol biosynthesis during spore germination of Botrytis cinerea, Venturia inaequalis and Puccinia graminis. J. Plant Pathol. 95:151-160.

Russel, P. E. 2004. Sensitivity Baselines in Fungicide Resistance Research and Management. FRAC Press, Brussels, Belgium.

Sang, M. K., Shrestha, A., Kim, D. Y., Park, K., Pak, C. H., and Kim, K. D. 2013 Biocontrol of Phytophthora blight and anthracnose in pepper by sequentially selected antagonistic rhizobacteria against Phytophthora capsici. Plant Pathol. J. 29:154-167.

Si, G., Zhang, J., Liu, L., Li, N., Zhan, M., and Chen, L. 2004a. Biological activity and application of a novel fungicide: SYP-Z048 (I). China J. Pesticides 43 16-18.

Si, G., Zhang, J., Liu, L., Li, N., Zhan, M., Chen, L., and Wang, L. Z. 2004b. Biological activity and application of a novel fungicide, SYP-Z048 (II). Chin J. Pesticides 43:61-63.

Sisler, H. D., and Ragsdale, N. N. 1984. Biochemical and cellular aspects of the antifungal action of ergosterol biosynthesis inhibitors. Br. Mycol. Soc. Symp. Ser. 21:398-400

Veloukas, T., and Karaoglanidis, G. S. 2012. Biological activity of the succinate dehydrogenase inhibitor fluopyram against Botrytis cinerea, and fungal baseline sensitivity. Pest Manag. Sci. 68:858-864.

Wang, Y., Meng, Y., and Zhang, M. 2011. Infection of Arabidopsis thaliana by Phytophthora parasitica and identification of variation in host specificity. Mol. Plant Pathol. 12:187-201.

Wong, F. P., and Midland, S. L. 2007. Sensitivity distributions of California populations of Colletotrichum cereale to the DMI fungicides propiconazole, myclobutanil, tebuconazole, and triadimefon. Plant Dis. 91: $1547-1555$. 
$\mathrm{Xu}$, C., Liang, X., and Hou, P. 2015. Effects of the novel fungicide benzothiostrobin on Sclerotinia sclerotiorum in the laboratory and on Sclerotinia stem rot in rape fields. Plant Dis. 99:969-975.

Zhang, C., Diao, Y., Wang, W., Hao, J., Imran, M., Duan, X., and Liu, L. 2017. Assessing the risk for resistance and elucidating the genetics of Colletotrichum truncatum that is only sensitive to some DMI fungicides. Front. Microbiol. 8:1779.
Zhang, Q., Liu, H., Wu, M., Xu, C., Sun, L., and Xu, H. 2012. Baseline sensitivity of Pestalotiopsis microspora, which causes black spot disease on Chinese hickory (Carya cathayensis), to pyraclostrobin. Crop Prot. 42:256-259.

Zhu, H., Huang, T., and Ji, M. S. 2016. Baseline sensitivity and control efficacy of pyrisoxazole against Botrytis cinerea. Eur. J. Plant Pathol. 146 315-323. 